\title{
THE STABILITY OF A WILSON TYPE AND A PEXIDER TYPE FUNCTIONAL EQUATION
}

\author{
YONG-SOO JUNG AND KIL-WOUNG JUN
}

\begin{abstract}
In this paper we study the stability of the Wilson type functional equation $f(x+y)-$ $f(x-y)=2 g(x) g(y)$ and the Pexider type functional equation $f(x+y-x y)=(1-x)^{\alpha} g(y)+$ $(1-y)^{\alpha} h(x)$, respectively.
\end{abstract}

Mathematics subject classification (2000): 39B52, 39B72.

Key words and phrases: functional equation, stability.

\section{REFERENCES}

[1] J. AcZÉL, Lectures on Functional Equations and Their Applications, Academic Press, New York/London, 1966.

[2] J. Aczél, J. Dhombres, Functional Equations in Several Variables, Cambridge Univ. Press, 1989.

[3] J. BAKER, The stability of the cosine equation, Proc. Amer. Math. Soc., 80 (1980), 411-416.

[4] P. W. Cholewa, The stability of the sine equation, Proc. Amer. Math. Soc., 88 (1983), 631-634.

[5] S. CZERWIK, On the stability of the quadratic mapping in normed spaces, Abh. Math. Sem. Hamburg, $62(1992), 59-64$.

[6] Z. DARÓCZY, Zs. PÁLES,, Functional Equations-Results and Advances, Kluwer Academic Publishers, Dordrecht/Boston/London, 2002.

[7] P. GǍVRUŢA, A generalization of the Hyers-Ulam-Rassias stability of approximately additive mappings, J. Math. Anal. Appl., 184 (1994), 431-436.

[8] R. GER, P. ŠEMrL, The stability of the exponential equation, Proc. Amer. Math. Soc., 124 (1996), $117-125$.

[9] D. H. HYERS, On the stability of the linear functional equation, Proc. Nat. Acad. Sci. U. S. A., 27 (1941), 222-224.

[10] G. ISAC, TH. M. RASSIAS, Functional inequalities for approximately additive mappings, in Stability of Mappings of Hyers-Ulam Type (Th. M. Rassias and J. Tabor, Eds.), (1994), 117-125, Hadronic Press, Palm Harbour, FL.

[11] S.-M. Jung, Hyers-Ulam-Rassias stability of a quadratic functional equation, J. Math. Anal. Appl., 232 (1999), 384-392.

[12] S.-M. Jung, On the superstability of the functional equation $f\left(x^{y}\right)=y f(x)$, Abh. Math. Sem. Univ. Hamburg, 67 (1997), 315-322.

[13] Y.-H. LEE, K.-W. JUN, A generalization of the Hyers-Ulam-Rassias stability of Pexider equation, J. Math. Anal. Appl., 246 (2000), 627-638.

[14] Gy. MAKsa, Problems 18, In Report on the 34th ISFE, Aequationes Math., 53 (1997), 194.

[15] Gy. MAKSA, Zs. PÁLES, Hyperstability of a class of linear functional equations, Acta Math. Acad. Paed. Nyhazi., 17 (2001), 107-112.

[16] TH. M. RASSIAS, On the stability of the linear mapping in Banach spaces, Proc. Amer. Math. Soc., 72 (1978), 297-300.

[17] TH. M. RASSIAS, On the stability of functional equations and a problem of Ulam, Acta Appl. Math., 62 (2000), 23-130. 
[18] TH. M. RASsiAs, On the stability of functional equations in Banach spaces, J. Math. Anal. Appl., 251 (2000), 264-284.

[19] TH. M. RASsiAs (ED.), Functional Equations and inequalities, Kluwer Academic, Dordrecht/ Boston/ London, 2000.

[20] TH. M. RASSIAS, J. TABOR, Stability of mappings of Hyers-Ulam type, Hadronic Press, Inc., Florida, 1994.

[21] TH. M. RASSIAS, On the the behavior of mappings which does not satisfy Hyers-Ulam stability, Proc. Amer. Math. Soc., 114 (1992), 989-993.

[22] TH. M. RASSIAS, J. TABOR, What is left of Hyers-Ulam stability?, Journal of Natural Geometry, 1 (1992), 65-69.

[23] F. SKOF, Sull'approssimazione delle appliazioni localmente $\delta$-additive, Atti Accad. Sc. Torino, 117 (1983), 377-389.

[24] J. TABOR, Stability of the Cauchy functional equation with variable bound, Publ. Math. Debrecen, 51 (1997), 165-173.

[25] S. M. Ulam, Problems in Modern Mathematics, Chap. VI, Wiley, New York, 1964. 